\title{
Discussing a challenging document focused on Land Use: The first bibliometric analysis of Laudato Si'
}

\author{
Paulo Mourao ${ }^{1}$ and Vitor Martinho ${ }^{2}$ \\ ${ }^{1}$ University of Minho \\ ${ }^{2}$ Polytechnic Institute of Viseu
}

May 5, 2021

\begin{abstract}
We live challenging times on several levels, and in this context the second encyclical, Laudato Si' (LS), of Pope Francis, published in 2015, has provided a special challenge for academics. As Pope Francis suggested in 2015, societies are challenged to modify the paradigms of life to achieve more sustainable development. LS has quickly become a widely quoted document, even by academics. This paper is the first bibliometric research about LS aiming to analyze this encyclical and explore several works published about LS between 2015 and 2020.To this end, we studied all documents published in the Web of Science Core Collection (238) and Scopus (222) about the topic "Laudato Si" in depth and analyzed them using bibliometric methods. The results show that there are scientific fields focused on studying LS in particular, namely Religious Sciences and the fields of Sustainability and Environment Studies. We also observed a small amount of networking among the authors publishing about LS.
\end{abstract}

\section{Hosted file}

mai21.pdf available at https://authorea.com/users/412106/articles/520895-discussing-achallenging-document-focused-on-land-use-the-first-bibliometric-analysis-of-laudato-si 